\title{
Patient-ventilator interaction and inspiratory effort during pressure support ventilation in patients with different pathologies
}

\author{
S. Nava*, C. Bruschi*, C. Fracchia*, A. Braschi**, F. Rubini*
}

Patient-ventilator interaction and inspiratory effort during pressure support ventilation in patients with different pathologies. S. Nava, C. Bruschi, C. Fracchia, A. Braschi, F. Rubini. (CERS Journals Ltd 1997.

ABSTRACT: The aim of this study was to evaluate whether pressure support ventilation (PSV) requires different diaphragmatic efforts and patient-ventilator matching, according to the underlying disease.

Four groups of patients requiring PSV were studied: Group A, recovering from an episode of acute respiratory failure due to adult respiratory distress syndrome (ARDS); Group B, with postsurgical complications; and two subsets of chronic obstructive pulmonary disease (COPD) patients, with "normal" static compliance of the respiratory system $\left(\boldsymbol{C}\right.$ st,rs) (Group C), or elevated $C_{\text {st,rs }}$ (Group D).

Ventilatory pattern, transdiaphragmatic pressure $\left(P_{\mathrm{di}}\right)$, the pressure-time product of the diaphragm (PTPdi), static (PEEPi,stat) and dynamic intrinsic positive end-expiratory pressure (PEEPi,dyn), $C_{\text {st, rs and resistance of the total respiratory }}$ system $(R \mathrm{rs})$ were recorded. The matching between patient and ventilator was analysed, recording the number of "ineffective efforts" (inspiratory efforts not efficient enough to trigger a new ventilator cycle, despite a positive deflection in $P$ di).

A satisfactory blood gas equilibrium arterial oxygen saturation $\left(S_{\mathrm{a}, \mathrm{O}_{2}}>\mathbf{9 3 \%}\right.$, with a $\mathrm{pH}>7.32$ ) was obtained in the various groups with different levels of PSV. Minute ventilation was found to be significantly higher in Groups A and B, due to the longer expiratory time $(t \mathrm{E})$ in the COPD groups. Group A ( 2 out of 7$)$, Group B (3 out of 7$)$, Group C ( 3 out of 5$)$ patients showed sporadic "ineffective efforts". All Group D patients manifested continuous mismatching with the ventilator, so that the pressure-time product of the diaphragm per minute (PTPdi/min), reflecting the metabolic work of the diaphragm, was not different in the four groups. Tidal volume and the spontaneous inspiratory efforts were similar in the four groups, but the number of breaths delivered by the ventilator was significantly higher in Groups $A$ and $B$.

The application of different levels of pressure support ventilation in patients with acute respiratory failure due to different pathologies, led them to breathe with comparable pressure time product of the diaphragm. The majority of the patients showed mismatching with the ventilator, although this effect was more pronounced in the groups with chronic obstructive pulmonary disease.

Eur Respir J., 1997; 10: 177-183.
*Pneumology Division of Centro Medico di Riabilitazione di Montescano, Fondazione Clinica del Lavoro IRCCS, Montescano, Italy. **Servizio di Rianimazione I, Ospedale Policlinico S. Matteo, IRCCS, Pavia, Italy.

Correspondence: S. Nava

Division of Pneumology

Centro Medico di Riabilitazione di Montescano 27040 Montescano [PV],

Italy

Keywords: Adult respiratory distress syndrome

chronic obstructive pulmonary disease ineffective efforts

postsurgical complications

pressure support ventilation

\section{Received: August 41995}

Accepted after revision August 251996
Pressure support ventilation (PSV) is an assisted mode of ventilation that supplies a constant level of positive airway pressure during spontaneous inspiratory efforts. It has classically been used in the weaning process of patients affected by acute respiratory failure due to different pathologies [1], and in the immediate period following cardiac surgery [2], since it has the ability to decrease the inspiratory work of breathing and inspiratory muscle effort $[3,4]$. The majority of studies concerning PSV have been performed in patients with acute respiratory failure (ARF), not homogeneously selected, some of them being affected by "acute" pathologies (adult respiratory distress syndrome (ARDS), postoperative complications, pulmonary embolism, congestive heart failure) and others by an acute exacerbation of chronic obstructive pulmonary disease (COPD).
These diseases are characterized by totally different respiratory mechanics and respiratory muscle function [5]. It is generally accepted that PSV may allow the patient to maintain control of inspiratory and expiratory time, and to interact with a set pressure to determine the ultimate flow and tidal volume [6]. We have recently shown, however, that this was not necessarily true in severe COPD patients with abnormally elevated static compliance of the respiratory system $(C$ st,rs $)$ [7]. In fact, at different levels of pressure support (PS) we found a mismatch between the ventilator and patient breathing frequencies, highlighted by the phenomenon of so-called "ineffective efforts". These were defined as inspiratory efforts not efficient enough to trigger a new ventilator cycle, despite a negative deflection in transdiaphragmatic pressure $(P \mathrm{di})$. 
We hypothesized that the work of the respiratory muscles, the patient-ventilator interaction and ventilatory pattern during PSV would be different depending on the underlying disease. We therefore studied the tensiontime product of the diaphragm (PTPdi) [8], the number of "ineffective efforts", together with the respiratory pattern "imposed" by the ventilator in four groups of patients ventilated with pressure support (PS) for ARF due to acute pathologies, such as ARDS, postsurgical complications, and two different subsets of COPD patients, characterized respectively by "normal" and "elevated" $C$ st,rs [9].

\section{Materials and methods}

Twenty four patients requiring mechanical ventilation for ARF were included in this study. Table 1 lists the characteristics pertinent to this study of the individual patients. Seven patients had postsurgery complications, seven had ARDS, and 10 COPD. The latter patients were divided into two subsets of five patients each, according to the value of $C$ st,rs (above or below $\left.88.5 \mathrm{~mL} \cdot \mathrm{cmH}_{2} \mathrm{O}^{-1}\right)$. This value was chosen to separate the COPD patients who were expected to be unweanable from mechanical ventilation from those expected to be weanable, according to a recent paper by ZANOTTI et al. [9]. ARDS was defined by the criteria proposed by MuRRAY et al. [10]. The ARDS score was $>2.5$ in all of the patients. The patients were studied at least 48 $\mathrm{h}$ after the beginning of PSV, when clinical conditions allowed this procedure. Criteria for initiating PSV were the following: 1) haemodynamic stability (regular cardiac rhythm and systolic blood pressure $>90 \mathrm{mmHg}$ ); 2)

Table 1. - Clinical and respiratory characteristics of the patients

\begin{tabular}{|c|c|c|c|c|}
\hline & Group A & Group B & Group C & Group D \\
\hline Sex F/M & $2 / 5$ & $1 / 6$ & $1 / 4$ & $1 / 4$ \\
\hline Age yrs & $59 \pm 6$ & $63 \pm 9$ & $63 \pm 9$ & $60 \pm 11$ \\
\hline$C_{\text {st, }, \mathrm{rs}} \mathrm{mL} \cdot \mathrm{cmH}_{2} \mathrm{O}^{-1}$ & $28.9 \pm 8.1^{* *}$ & $39.6 \pm 7.7+$ & $62.1 \pm 6.5$ & $102.6 \pm 7.3$ \\
\hline$R \mathrm{rs} \quad \mathrm{cmH}_{2} \mathrm{O} \cdot \mathrm{L}^{-1} \cdot \mathrm{s}$ & $22.2 \pm 4.8$ & $16.5 \pm 4.0$ & $19.2 \pm 7.3$ & $23.3 \pm 6.0$ \\
\hline$R \mathrm{rs}$, corr $\mathrm{cmH}_{2} \mathrm{O} \cdot \mathrm{L}^{-1} \cdot \mathrm{s}$ & $18.1 \pm 4.0$ & $12.9 \pm 3.7$ & $16.5 \pm 6.8$ & $19.6 \pm 5.2$ \\
\hline$P 0.1 \quad \mathrm{cmH}_{2} \mathrm{O}$ & $3.5 \pm 1$ & $2.9 \pm 1.3$ & $3.3 \pm$ & $3.9 \pm 0.5$ \\
\hline $\mathrm{PEEPi}$,dyn $\mathrm{cmH}_{2} \mathrm{O}$ & $3.1 \pm 1.6$ & $2.7 \pm 1.1$ & $3.2 \pm 1.9$ & $4.0 \pm 1.3$ \\
\hline $\begin{array}{l}\mathrm{PEEPi} \text {,dyn at ZEEP } \\
\mathrm{cmH}_{2} \mathrm{O}\end{array}$ & $7.3 \pm 1.6^{* *}$ & $6.2 \pm 0.07^{*}$ & $* 3.2 \pm 1.9$ & $4.0 \pm 1.3$ \\
\hline PEEPext $\mathrm{c}$ & & $4.0 \pm 0.6$ & & \\
\hline PEEPi,stat $\mathrm{cmH}_{2} \mathrm{O}$ & $9.3 \pm 2.5^{* * *}$ & $7.8 \pm 1.1$ & $4.4 \pm 1.9$ & $5.5 \pm 1.2$ \\
\hline
\end{tabular}

Values are presented as mean \pm SD. F: female; M: male; $C_{\text {st,rs: }}$ static compliance of respiratory system; $R \mathrm{rs}$,corr: total inspiratory resistance of respiratory system corrected for the endotracheal tube; Rrs: total inspiratory resistance of respiratory system not corrected for the endotracheal tube; $P_{0.1}$ : mouth occlusion pressure after $100 \mathrm{~ms}$; PEEPi,dyn: dynamic intrinsic positive end-expiratory pressure recorded above extrinsic PEEP; PEEPi,dyn at ZEEP: dynamic intrinsic positive end-expiratory pressure recorded at zero positive end-expiratory pressure (ZEEP); PEEPext: external positive end-expiratory pressure; PEEPi,stat: static intrinsic positive end-expiratory pressure. See text for explanation of groups. ${ }^{* *}: \mathrm{p}<0.05$ Group A versus Groups C and D; *: $\mathrm{p}<0.05$ Group B versus Groups C and D; ${ }^{+}$: $\mathrm{p}<0.05$ Group B versus Group D. a spontaneous respiratory frequency $(f \mathrm{R})>8$ breaths $\cdot$ min $^{-1}$ when mechanical ventilatory support was briefly discontinued; 3 ) neuromuscular drive, as assessed by mouth occlusion pressure $\left(P_{0.1}\right)<6 \mathrm{cmH}_{2} \mathrm{O}$; and 4) good patient compliance to this mode of ventilation, with no need for sedation.

The level of PS was that applied by the attending physician, according to "common" clinical experience and defined as the lowest sufficient to obtain a satisfactory blood gas equilibrium (arterial oxygen saturation $\left(S \mathrm{a}, \mathrm{O}_{2}\right)>93 \%$ with a level of arterial carbon dioxide tension $\left(\mathrm{Pa}_{\mathrm{a}} \mathrm{CO}_{2}\right)$ which resulted in a $\mathrm{pH}$ of $\left.\geq 7.32\right)$ and good patient compliance to the ventilation mode. Patients with a $f \mathrm{R}$ greater than 40 breaths $\cdot \mathrm{min}^{-1}$ were excluded from the study, since it has been suggested that during PSV the $f_{\mathrm{R}}$ should be kept below that level [11, 12]. All the measurements were performed at a constant inspiratory oxygen fraction $\left(F_{1}, \mathrm{O}_{2}\right)$. Patients were studied in semirecumbent position. The study was approved by the Local Ethics Committee and informed consent was obtained.

\section{Measurements}

Airway pressure $(P$ aw $)$ was recorded at the distal end of the endotracheal tube or cannula with a differential pressure transducer (Honeywell $\pm 300 \mathrm{cmH}_{2} \mathrm{O}$; Freeport, IL, USA). Transdiaphragmatic pressure $(P$ di) was calculated as the difference between gastric $(P$ ga $)$ and oesophageal $(P$ oes $)$ pressures and was measured using balloon-catheter systems. One balloon was positioned in the middle third of the oesophagus [13], and was filled with 0.5 $\mathrm{mL}$ of air; the second balloon was placed in the stomach and inflated with $1 \mathrm{~mL}$ of air. The occlusion test was used to check the position of the oesophageal balloon [14]. The pressures were recorded using a differential transducer (Honeywell $\pm 300 \mathrm{cmH}_{2} \mathrm{O}$; Freeport, IL, USA). Dynamic intrinsic positive end-expiratory pressure (PEEPi,dyn) was measured as the amount of negative deflection in $P$ oes preceding the start of inspiratory flow, and subtracting from this value the decrease in $P$ ga, if any, during this time interval [15].

Airflow was measured with a pneumotachograph (Screenmate box 0586; Jaeger Gmbh, Hochberg, Germany) positioned between the endotracheal tube or the tracheal cannula and the $\mathrm{Y}$ of the ventilatory tubings. Tidal volume $(V \mathrm{~T})$ was obtained by integration of the flow signal. The inspiratory $(t \mathrm{I})$, expiratory $(t \mathrm{E})$ and total breathing cycle durations $(t$ tot $)$ delivered by the ventilator were also calculated from the flow. The spontaneous $f$ R was recorded from the $P$ di traces, and calculated as the number of $P$ di positive deflections during a $5 \mathrm{~min}$ recording characterized by a regular breathing pattern. The pressure-time product of the diaphragm (PTPdi) was calculated, on a breath-by-breath basis (PTPdi/b) and per minute (PTPdi/min); it was measured as the area subtended by $P$ di above its expiratory baseline over $t$ I [16]. In measuring PTPdi, we also took into consideration the component due to PEEPi. PTPdi-PEEPi was defined as the subtended area corresponding to the initial portion of $P \mathrm{di}$, encompassed between the onset of its positive deflection and the point on $P$ di corresponding to zero flow. 
Table 2. - Ventilatory settings in the controlled mode during the recording of respiratory mechanics

\begin{tabular}{lllll}
\hline & Group A & Group B & \multicolumn{1}{c}{ Group C } & Group D \\
\hline$f_{\mathrm{R}}$ breaths $\cdot \mathrm{min}^{-1}$ & $24.4 \pm 4.7$ & $23.6 \pm 4.3$ & $15.3 \pm 3.0$ & $12.0 \pm 3.9$ \\
$V_{\mathrm{T}} \mathrm{mL} \cdot \mathrm{kg}^{-1}$ & $7.31 \pm 0.8$ & $8.31 \pm 1.1$ & $8.72 \pm 2.8$ & $8.70 \pm 2.6$ \\
$t \mathrm{I} \mathrm{S}$ & $0.88 \pm 0.11$ & $0.87 \pm 0.09$ & $1.12 \pm 0.21$ & $1.29 \pm 0.019$ \\
$t \mathrm{E} \mathrm{S}$ & $1.55 \pm 0.19$ & $1.64 \pm 0.17$ & $2.87 \pm 0.26$ & $3.99 \pm 0.61$ \\
\hline
\end{tabular}

Values are presented as mean \pm SD. $f \mathrm{R}$ : respiratory frequency; $V$ T: tidal volume; $t \mathrm{t}$ : inspiratory time; $t \mathrm{E}$ : expiratory time. See text for explanation of groups.

The airway pressure developed in the first $100 \mathrm{~ms}$ after the onset of the inspiratory effort made after end-expiratory occlusion $(P 0.1)$ [17], was obtained, during PSV, by pressing the hold button on the ventilator. The pressure signal was recorded and analysed with a computerized program (see data analysis section). The value of $P 0.1$ was calculated as the mean of three measurements.

Measurements of respiratory mechanics were obtained in all patients, after having them paralysed, with a ventilatory setting aimed to simulate their breathing pattern. Table 2 illustrates the ventilatory parameters employed in the controlled mode to record respiratory mechanics. Intrinsic static positive end-expiratory pressure (PEEP $i$, stat) was measured with the end-expiratory occlusion technique [18]. Briefly, after several breaths under controlled mechanical ventilation, the airway opening was occluded at the end of a tidal expiration, using the end-expiratory hold button. All the patients studied showed a positive $P$ aw during the occlusion and exhibited a plateau which represents the elastic recoil pressure; this value provides a direct measurement of PEEPi,stat. $C$ st,rs was calculated during an occlusion at end-inspiration, as the ratio between the inspiratory $V_{\mathrm{T}}$ and the difference between the end-inspiratory and the end-expiratory (PEEPi,stat) plateau pressures [19]. The end-inspiratory occlusion also allows the determination of the resistive properties of the respiratory system, as described in detail previously [20]. In calculating the resistance of the respiratory system, we subtracted the resistance of the endotracheal tube (internal diameter range 6.5-8 $\mathrm{mm}$ ) [21], and corrected the errors due to the closing time of the ventilator valve [22].

Blood was withdrawn from the radial artery and blood gas levels were recorded using a blood gas analyser (ABL 500 Radiometer; Copenhagen, Denmark).

\section{Protocol}

Mechanical ventilation was delivered by Cesar (Taema, France) or Amadeus (Hamilton Medical, Rhazuns, Switzerland) ventilators. In the PSV mode, the pressure trigger was set constant throughout the study at the minimum pressure to avoid auto-triggering (usually $-1 \mathrm{cmH}_{2} \mathrm{O}$ ).

The patients were ventilated with a constant $F_{\mathrm{I}, \mathrm{O}_{2}}$ able to maintain an $\mathrm{Sa}, \mathrm{O}_{2}>93 \%$. All the patients were studied for $45 \mathrm{~min}$, with their usual PS and the minimal external positive end-expiratory pressure (PEEPext) sufficient to achieve the target $\mathrm{Sa}_{\mathrm{a}} \mathrm{O}_{2}$ (table 3). PEEPext was not applied in COPD patients, and was briefly removed in ARDS and postsurgical patients, at the beginning of the trial, to assess the PEEPdyn at zero positive end-expiratory pressure (ZEEP). At the end of the PSV trials the
Table 3. - Arterial blood gas values during PSV

\begin{tabular}{|c|c|c|c|c|}
\hline & Group A & Group B & Group C & Group D \\
\hline pH & $7.42 \pm 0.10$ & $7.44 \pm 0.08$ & $7.38 \pm 0.12$ & $7.36 \pm 0.11$ \\
\hline$P \mathrm{a}, \mathrm{O}_{2} \quad \mathrm{kPa}$ & $10.6 \pm 1.3$ & $11.8 \pm 1.1$ & $9.8 \pm 0.8$ & $10.1 \pm 1.2$ \\
\hline $\mathrm{mmHg}$ & $79.3 \pm 10.1$ & $88.5 \pm 8.1$ & $73.2 \pm 5.8$ & $75.5 \pm 8.7$ \\
\hline$P \mathrm{a}, \mathrm{CO}_{2} \mathrm{kpa}$ & $4.6 \pm 0.1$ & $5.4 \pm 0.3$ & $6.6 \pm 1.1$ & $6.9 \pm 1.0$ \\
\hline $\mathrm{mmHg}$ & $34.5 \pm 1.1$ & $40.2 \pm 2.2$ & $49.9 \pm 8.2$ & $52.0 \pm 7.9$ \\
\hline$F_{\mathrm{I}, \mathrm{O}_{2}} \%$ & $0.59 \pm 0.07$ & $0.49 \pm 0.04$ & $0.32 \pm 0.03$ & $0.31 \pm 0.03$ \\
\hline
\end{tabular}

Values are presented as mean \pm SD. $P$ a, $\mathrm{O}_{2}$ : arterial oxygen tension; $P$ a, $\mathrm{CO}_{2}$ : arterial carbon dioxide tension; $\mathrm{F}_{\mathrm{I}}, \mathrm{O}_{2}$ : fraction of inspired oxygen. See text for explanation of groups.

subjects were sedated with diazepam $\left(0.1-0.2 \mathrm{mg} \cdot \mathrm{kg}^{-1}\right)$, paralysed with pancuronium bromide $\left(0.1-0.2 \mathrm{mg} \cdot \mathrm{kg}^{-1}\right)$, and switched to controlled mode at ZEEP to study the respiratory mechanics.

\section{Data analysis}

Mean $P$ di, $P$ oes, $P$ ga, PTPdi/b, were calculated, averaging the values from five regular breaths; PTPdi was also recorded per minute; in calculating PTPdi/min every $P$ di positive swing was analysed, irrespective of whether this inspiratory effort was able to trigger the ventilator or not. Minute ventilation and respiratory timing (inspiratory time $(t \mathrm{I})$, expiratory time $(t \mathrm{E})$, total respiratory cycle time $(t$ tot $)$, duty cycle $\left.\left(t_{\mathrm{I}} / t_{\mathrm{tot}}\right)\right)$ were measured from the flow traces during a 5 min recording characterized by a regular breathing pattern. At the same time, the "spontaneous" $f_{\mathrm{R}}$, defined as all the inspiratory efforts calculated on the $P$ di trace, was also recorded. In this way, it was possible to detect the numbers of the socalled "ineffective efforts", defined as inspiratory efforts not efficient enough to trigger a new ventilator cycle, despite a positive deflection in $P$ di. All the variables were recorded on a paper recorder (Gould TA 4000; Valley View, OH, USA) and on a personal computer by an analogue-to-digital (A/D) board, at the sampling frequency of $60 \mathrm{~Hz}$. Data analysis was performed with a computerized program (Labdat and Anadat, by J. Bates, MeakinsChristie Laboratories, McGill University, Montreal, PQ, Canada).

Results are expressed as mean values \pm SD. The KruskalWallis one-way analysis by ranks was used to analyse the differences between the groups of patients. Correlation analysis was performed using Pearson's correlation coefficient. Statistical significance was defined as a two tailed p-value less than 0.05 .

\section{Results}

The patients required different levels of PS to achieve good compensation of blood gases (table 3). Mean PS was $24.4 \pm 2.1 \mathrm{cmH}_{2} \mathrm{O}$ for ARDS patients, 20.9 \pm 3.0 $\mathrm{cmH}_{2} \mathrm{O}$ for postsurgical patients, and $15.9 \pm 3.3$ and $16.5 \pm$ $2.2 \mathrm{cmH}_{2} \mathrm{O}$ for COPD patients of Group C and D, respectively, but the differences were not statistically different. During the trial, none of the patients showed, a significant positive deflection of $P_{\text {oes }}\left(>3 \mathrm{cmH}_{2} \mathrm{O}\right)$ at the end of inspiration [23].

Table 4 shows the ventilatory variables during PSV and the spontaneous breathing rate prior to intubation, 
Table 4. - Ventilatory variables during PSV

\begin{tabular}{|c|c|c|c|c|}
\hline & Group A & Group B & Group C & Group D \\
\hline$V^{\prime} \mathrm{E} \quad \mathrm{L} \cdot \mathrm{kg}^{-1} \cdot \mathrm{min}$ & $0.27 \pm 0.04 *$ & $0.29 \pm 0.03 *$ & $0.19 \pm 0.03$ & $0.14 \pm 0.04$ \\
\hline$V_{\mathrm{T}} \quad \mathrm{mL} \cdot \mathrm{kg}^{-1}$ & $6.95 \pm 1.2$ & $7.80 \pm 1.4$ & $7.91 \pm 3.1$ & $8.13 \pm 3.3$ \\
\hline$t \mathrm{I} \quad \mathrm{s}$ & $0.94 \pm 0.13$ & $0.92 \pm 0.12$ & $1.13 \pm 0.22$ & $1.37 \pm 0.23$ \\
\hline$t \mathrm{E} \mathrm{S}$ & $1.64 \pm$ & & 2.97 & $4.15 \pm 0.71$ \\
\hline$t$ tot $\mathrm{s}$ & $2.58 \pm 0.24 *$ & $2.70 \pm$ & $4.1 \pm 0.62$ & $5.52 \pm 0.93$ \\
\hline$f_{\mathrm{R}}$ breaths $\cdot \min ^{-1}$ & $23.2 \pm 5.3^{*}$ & $22.2 \pm 7.1 *$ & $14.6 \pm$ & $10.9 \pm 5.6$ \\
\hline $\begin{array}{l}f_{\mathrm{R}, \mathrm{sb}} \\
\quad \text { breaths } \cdot \mathrm{min}^{-1}\end{array}$ & $40.2 \pm 11.2^{+}$ & $38.5 \pm 8.8^{+}$ & $26.4 \pm 9.2$ & $23.2 \pm 6.6$ \\
\hline $\begin{array}{l}f_{\mathrm{R}, P \mathrm{di}} \\
\quad \text { breaths } \cdot \mathrm{min}^{-1}\end{array}$ & $24.4 \pm 4.4$ & $23.7 \pm 6.0$ & $18.1 \pm 2.9$ & $19.6 \pm 4.9$ \\
\hline
\end{tabular}

Values are presented as mean \pm SD. $V^{\prime} \mathrm{E}$ : minute ventilation; $V_{\mathrm{T}}$ : expiratory tidal volume; $t \mathrm{I}$ : inspiratory time; $t \mathrm{E}$ : expiratory time; $t$ tot: total respiratory cycle time; $f \mathrm{R}$ : respiratory frequency recorded from the flow signal; $f_{\mathrm{R}}$, sb: respiratory frequency during spontaneous breathing prior to intubation; $f_{\mathrm{R}}, P \mathrm{di}$ : respiratory frequency during pressure support ventilation, recorded from the transdiaphragmatic pressure trace. See text for explanation of groups. *: $<<0.05$ Group A and B $v s$ Group $\mathrm{C}$ and $\mathrm{D} ;{ }^{+}: \mathrm{p}<0.05 f \mathrm{R}, \mathrm{sb}$ vs $f_{\mathrm{R}}$ and $f_{\mathrm{R}, P \mathrm{di}}$.

in the four groups. The application of PSV reduced the $f_{\mathrm{R}}$ in all of the patients. A significant difference was observed in the respiratory rate delivered by the ventilator between Groups $\mathrm{A}$ and $\mathrm{B}$ versus $\mathrm{C}$ and $\mathrm{D}$, but this was not confirmed when the $f_{\mathrm{R}}$ was analysed from the $P$ di traces. In Groups A and B the $f$ R recorded before intubation was significantly higher than that measured from the $P$ di trace during PSV. Minute ventilation was found to be significantly higher in Groups A and B; this was mainly due to the different breathing pattern delivered by the ventilator in the four groups, $V_{\mathrm{T}}$ being similar. Expiratory tidal volume ranged $5.8-11.8 \mathrm{~mL} \cdot \mathrm{kg}^{-1}$. Respiratory frequency, $t \mathrm{E}$, and $t \mathrm{I} / t$ tot were also significantly different in COPD patients, while $t$ I was slightly but not significantly longer in these latter groups.

PEEPi,stat, PEEPi,dyn and PEEPext values are shown in table 1. It can be noted that, in all of the groups, values of PEEPi,stat recorded in the controlled mode simulating the breathing pattern during PSV overestimate the values of PEEPi,dyn recorded without the addition of PEEPext; this was more apparent in the patients who showed a substantial contribution from the abdominal muscle during expiration.

As shown in table 5, the PTPdi/b was similar during PSV in the four groups: $5.77 \pm 2.27 \mathrm{cmH}_{2} \mathrm{O} \cdot \mathrm{s}^{-1}$ in patients with ARDS; $5.68 \pm 1.56 \mathrm{cmH}_{2} \mathrm{O} \cdot \mathrm{s}^{-1}$ in postsurgical patients; $5.86 \pm 1.94$ and $6.43 \pm 1.33 \mathrm{cmH}_{2} \mathrm{O} \cdot \mathrm{s}^{-1}$ in COPD

Table 5. - Pressure-time product during PSV

\begin{tabular}{lcccc}
\hline & Group A & Group B & Group C & Group D \\
\hline $\begin{array}{c}\mathrm{PTPdi} / \mathrm{b} \\
\mathrm{cmH}\end{array} \mathrm{O}_{2} \mathrm{O} \cdot \mathrm{s}^{-1}$ & $5.77 \pm 2.27$ & $5.68 \pm 1.56$ & $5.86 \pm 1.94$ & $6.43 \pm 1.33$ \\
$\begin{array}{c}\mathrm{PTPdi}-\mathrm{PEEP} / \mathrm{b} \\
\mathrm{cmH} \mathrm{H}_{2} \mathrm{O} \cdot \mathrm{s}^{-1}\end{array}$ & $1.12 \pm 0.38$ & $1.01 \pm 0.22$ & $1.37 \pm 0.19$ & $1.30 \pm 0.31$ \\
$\begin{array}{c}\mathrm{PTPdi} / \mathrm{min} \\
\mathrm{cmH} \mathrm{O}_{2} \mathrm{O} \cdot \mathrm{s}^{-1}\end{array}$ & $135 \pm 30$ & $129 \pm 37$ & $105 \pm 30$ & $137 \pm 34$ \\
\hline
\end{tabular}

Values are presented as mean \pm SD. PTPdi/b: the diaphragmatic pressure-time product for a single breath (average of five breaths); PTPdi-PEEPi/b: the diaphragmatic pressure-time product due to dynamic intrinsic positive end-expiratory pressure for a single breath (average of five breaths); PTPdi/min: the diaphragmatic pressure-time product recorded during a minute of regular respiration. See text for explanation of groups. patients with normal and abnormal $C_{\text {st,rs, }}$ respectively. The PTPdi-PEEPi accounted for approximately $20 \%$ of the total PTPdi. The PTPdi depends on the amplitude of $P$ di swings and the time the contraction is maintained. $P$ di did not differ between the groups of patients and the $t$ I was longer, although not significantly so, in COPD patients; however, whilst in the patients with acute pathologies the $P$ di swing was always approximately synchronous with the inspiratory flow, as usually observed in spontaneous breathing, in COPD patients the $P$ di swing always crossed the zero baseline much before the end of inspiratory flow. This typical pattern is illustrated for two representative patients from Group A and D in figure 1. Despite the fact that PTPdi/b was similar in the four groups and the $f_{\mathrm{R}}$, recorded from the flow trace, much greater in non-COPD patients, the PTPdi/min was not different in the various groups (table 5). This was due to the greater number of ineffective efforts in COPD patients, resulting in wasting of diaphragmatic energy expenditure (fig. 1b).

Table 6 illustrates, for individual patients, the occurrence of these ineffective efforts, over a period of $5 \mathrm{~min}$

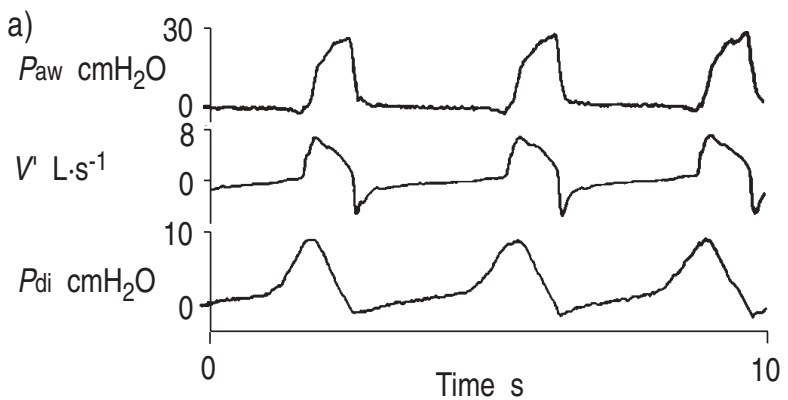

b)

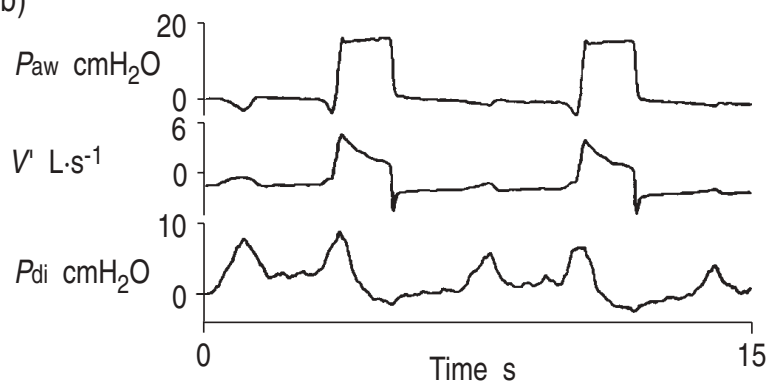

Fig. 1. - Polygraphic recording during pressure support ventilation (PSV) in two representative patients from: a) Group A with ARDS; and b) Group D with COPD. Paw: airway pressure; $V^{\prime}$ : airflow; $P_{\mathrm{di}}$ : transdiaphragmatic pressure. Note the difference in the time scale and the presence of several ineffective efforts in the Group D subject. See text for further details and explanation of groups.

Table 6. - Ineffective efforts during PSV

\begin{tabular}{|c|c|c|c|c|c|c|c|}
\hline \multicolumn{2}{|c|}{ Group A } & \multicolumn{2}{|c|}{ Group B } & \multicolumn{2}{|c|}{ Group C } & \multicolumn{2}{|c|}{ Group D } \\
\hline $\begin{array}{l}\mathrm{Pt} \\
\text { No. }\end{array}$ & $\begin{array}{l}\text { ineff/eff } \\
\text { breaths }\end{array}$ & $\begin{array}{c}\mathrm{Pt} \\
\text { No. }\end{array}$ & $\begin{array}{l}\text { ineff/eff } \\
\text { breaths }\end{array}$ & $\begin{array}{l}\mathrm{Pt} \\
\text { No. }\end{array}$ & $\begin{array}{l}\text { ineff/eff } \\
\text { breaths }\end{array}$ & $\begin{array}{c}\mathrm{Pt} \\
\text { No. }\end{array}$ & $\begin{array}{l}\text { ineff/eff } \\
\text { breaths }\end{array}$ \\
\hline 3 & $1 / 5.2$ & 1 & $1 / 10.5$ & 1 & $1 / 3.2$ & 1 & $1 / 5.5$ \\
\hline 7 & $1 / 4.0$ & 3 & $1 / 2.3$ & 2 & $1 / 4.8$ & 2 & $1 / 2.6$ \\
\hline & & 4 & $1 / 5.5$ & 5 & $1 / 3.4$ & 3 & $2 / 1.5$ \\
\hline & & & & & & 4 & $1 / 1.8$ \\
\hline & & & & & & 5 & $1 / 7.4$ \\
\hline
\end{tabular}

Patient-ventilator mismatching. Individual value of the ratio ineffective/effective (ineff/eff) breaths recorded in the patients that showed this phenomenon, during $5 \mathrm{~min}$ of regular breathing. See text for explanation of groups. 
of regular breathing. Patient-ventilator mismatching was observed in more than half of the patients (13 out of 24) but with different proportions in the four groups: being 2 out of 7 (29\%) in Group A; 3 out of 7 (43\%) in Group B; 3 out of $5(60 \%)$ in Group C; and 5 out of $5(100 \%)$ in Group D. Correlations between the rate of ineffective efforts and some physiological variables were performed by grouping all patients together, giving a value of zero for patients without ineffective efforts. There were significant degrees of correlation between the number of ineffective efforts and the duration of diaphragmatic contraction calculated from $P$ di, expressed as a percentage of $t$ I calculated on the flow trace $(\mathrm{r}=0.66$; $\mathrm{p}<0.01)$, as well as with the $C$ st, rs $(\mathrm{r}=0.54 ; \mathrm{p}<0.05)$, but not with $P 0.1$, recorded during PSV.

\section{Discussion}

In the present study, we have shown that patients affected by different pathologies and ventilated, according to "common" clinical experience, with different levels of PS, have comparable diaphragmatic energy expenditure, although the breathing pattern delivered by the ventilator varied depending on the underlying disease. Indeed, as already observed in severe COPD patients [7], a mismatching between patient and ventilator was observed in more than half of those studied. This phenomenon although more apparent in the patients affected by COPD was not a unique feature of this group.

PSV is an assisted mode of ventilation now widelyused in the treatment of ARF due to various pathologies. It has also been shown that PSV significantly reduces the duration of mechanical ventilation, since the weaning process is faster, as compared to the assist/control mode and to the traditional weaning trial with a Tpiece [1]. During PSV, inspiratory muscle effort can be reduced, or almost totally eliminated, depending on the level of inspiratory support $[3,4]$, while the patient is able to maintain total control of the respiratory timing, determining the ultimate flow and tidal volume [6]. However, all these conclusions are based on several studies performed on heterogeneous selected groups of patients affected by "acute pathologies" on previously normal respiratory systems, or acute exacerbations of chronic pulmonary disease. Despite the efforts made by several researchers, up to the present time, there is no recognized "gold standard" for the level at which the support must be set. The patients we studied were ventilated with a level of pressure support chosen by the caring physician, following some simple rules drawn from clinical practice, such as the lowest $V_{\mathrm{T}}$ able to achieve a satisfactory blood gas equilibrium, a $f_{\mathrm{R}}<40$ breaths $\cdot \mathrm{min}^{-1}$, and a good compliance by the patient to this mode of ventilation.

We found that despite the different levels of PS applied in the various pathologies, all the patients were able to achieve the above-mentioned conditions, with similar tidal volumes. This was obtained with different levels of PS, starting from $15.9 \mathrm{cmH}_{2} \mathrm{O}$ for COPD patients and reaching $24.4 \mathrm{cmH}_{2} \mathrm{O}$ for ARDS patients; this wide range is probably due to the difference in the compliance of the respiratory system, low in Group A and B [24] and normal or elevated in Groups C and D. The other interesting observation is that the application of these different levels of PS led patients of the various groups to breathe with comparable diaphragmatic energy expenditure expressed both per breath and per minute. The PTPdi is an index of respiratory muscle activity, since it has been shown to be correlated with the oxygen consumption of these muscles [8]. The diaphragmatic energy expenditure depends not only on the amplitude of the pressure generated, but also on the length of time the contraction is maintained (i.e. inspiratory time), and when calculated over a time interval on the respiratory frequency. As shown in table 5, no significant differences were observed in the PTPdi/b in the various groups; this happened because the inspiratory time was slightly shorter in Groups $\mathrm{A}$ and $\mathrm{B}$, while the $P$ di inspiratory swings were slightly smaller in Groups $C$ and D.

A rather surprising observation is that the PTPdi/min was also similar in the four groups, despite the fact that $f_{R}$, recorded on the flow traces, was apparently markedly different in ARDS and postsurgical patients, as compared to COPD patients. The first two groups were in fact characterized by a higher $f \mathrm{R}$; however, when this was calculated on the $P$ di trace, a reflection of "true" patient $f_{\mathrm{R}}$, no significant difference was observed in the four groups. This underlines the importance of the "wasted" efforts during PSV, and it follows that similar breathing patterns may result in different efficiencies of PSV in assisting spontaneous breathing in proportion to the different rates of wasted efforts.

We have recently demonstrated significant ventilatorpatient mismatching in COPD patients [7]. Based on the results of that study, we suggested, and have confirmed in the present study, that the patient-ventilator mismatching was dependent mainly on the elevated $C$ st,rs and on the high level of auto-PEEP. In fact, the ventilator $t \mathrm{I}$ is mainly dependent on the degree of distensibility of the respiratory system and on the operator setting (i.e. the level of support and the flow threshold that has to be reached to cycle expiration). In severe COPD, but not in other pathologies (fig. 1), the machine inflated the patient long after the inspiratory muscles had stopped their contraction, indicating that a significant part of inspiration was passively driven by the ventilator alone, despite apparently no excess of support having been given by the caring physician, as demonstrated by a marked positive deflection in $P$ oes during the late inspiratory phase [23].

Based on this mechanism, the following inspiratory effort is likely to happen at a high lung volume, when the pressure at the airway opening is still significantly positive. Therefore, we postulated that the inspiratory effort would not be sufficient to create a pressure gradient capable of being sensed by the ventilator, and that the application of external PEEP may help in reducing the number of ineffective efforts. This was confirmed by the significant correlation observed between the number of ineffective efforts and the duration of the diaphragmatic contraction $(P \mathrm{di})$, expressed as percentage of the ventilator inspiratory time. One may also argue that setting the PS lower in COPD groups, for example according to the patients' "real" respiratory rate, would result in a different frequency of ineffective efforts. We have, however, previously demonstrated that lowering the PS 
level brought a marked increase in PTPdi, and even more importantly a deterioration in arterial blood gas values [7].

The results of the present study demonstrate that the ineffective efforts phenomenon is not a feature peculiar to COPD patients, and this is rather surprising considering that the Group A and B patients had a $C$ st,rs below the normal range [24]. Some considerations, need, however to be made. Firstly, the presence of patient-ventilator mismatching was, even in this study, more frequent in COPD subjects with severely altered respiratory mechanics and higher level of PEEPi (namely Group D), as compared to the other group of COPD patients with normal $C$ st,rs; suggesting that, at least in COPD, the degree of distensibility of the respiratory system may actually play a paramount role in the genesis of the ineffective efforts. The division of COPD patients into two groups according to the value of $C$ st,rs was arbitrarily made according to the results of a recent paper [9], in which patients with lower elastance (i.e. higher degree of pulmonary emphysema) were more difficult to wean from mechanical ventilation than patients with normal elastance. Secondly, the presence of patient-ventilator mismatching was observed in Groups A and B, but only in the subgroup of patients ( 5 out of $14=35 \%$ ) with a higher $f_{\mathrm{R}}$ (range $26-37$ breaths $\cdot \mathrm{min}^{-1}$ ) and PEEPi,dyn, ranging 5.9-13.4 $\mathrm{cmH}_{2} \mathrm{O}$. The increased $f_{\mathrm{R}}$, and the short expiratory time $(0.92 \pm 0.08 \mathrm{~s})$ together with the high levels of resistances may lead, in this subgroup of patients, to the genesis of dynamic hyperinflation. The role of elevated PEEPi,dyn in the genesis of the ineffective efforts, has already been described in a case report [25], and confirmed by the fact that the application of an external PEEP may in fact reduce the degree of mismatching [7].

A theoretical problem in comparing the different ventilatory patterns may be the fact that the Group A and $B$ patients were ventilated with the addition of an external PEEP, while the COPD patients were not. This was done for clinical reasons, since the addition of a small amount of external PEEP was mandatory to achieve a compensation in terms of gas exchange $\left(\mathrm{Sa}_{\mathrm{a}} \mathrm{O}_{2}>93 \%\right)$, not possible without this procedure. It is to be noted, however, that extrinsic PEEP was titrated at about $60 \%$ of the PEEPi,stat and, therefore, a relatively large amount of PEEPi,dyn was still present, despite the addition of external PEEP. As shown in table 1 this amount was similar in the four groups, making us quite confident that all the patients were studied with a similar degree of mechanical load before starting the next inspiration.

In conclusion, we have shown that different levels of pressure support, applied following common clinical criteria to patients affected by different pathologies recovering from acute respiratory failure, may lead to similar levels of expired tidal volume and a similar degree of diaphragmatic energy expenditure, but that the breathing frequency delivered by the ventilator is not always matched to the patient's effort. In particular, the patients with more severe chronic obstructive pulmonary disease showed a high number of wasted efforts that caused a very prolonged expiratory time, and slow respiratory rate. Conversely, in patients affected by adult respiratory distress syndrome or postsurgical complications, the occurrence of wasted efforts was reduced, as compared to chronic obstructive pulmonary disease, but not completely eliminated, and they adopted a faster breathing frequency and higher minute ventilation. Patient-ventilator mismatching is a frequent feature during pressure support ventilation and is not unique to patients with chronic obstructive pulmonary disease; close monitoring of the patient-machine interaction is mandatory when titrating the levels of inspiratory support and external positive end-expiratory pressure.

Acknowledgement: The authors wish to thank R.C. Stenner for kindly reviewing the English in this manuscript.

\section{References}

1. Brochard L, Rauss A, Benito S, et al. Comparison of three methods of gradual withdrawal from ventilatory support during weaning from mechanical ventilation. Am J Respir Crit Care Med 1994; 150: 896-903.

2. Prakash O, Meij S. Cardiopulmonary response to inspiratory pressure support during spontaneous ventilation vs conventional ventilation. Chest 1985; 88: 403-408.

3. Brochard L, Pluskwa F, Lemaire F. Improved efficacy of spontaneous breathing with inspiratory pressure support. Am Rev Respir Dis 1987; 136: 411-415.

4. Brochard L, Harf A, Lorino H, Lemaire F. Inspiratory pressure support prevents diaphragmatic fatigue during weaning from mechanical ventilation. Am Rev Respir Dis 1989; 139: 513-521.

5. Broseghini C, Brandolese R, Poggi R, et al. Respiratory mechanics during the first day of mechanical ventilation in patients with pulmonary edema and chronic airflow obstruction. Am Rev Respir Dis 1988; 138: 355-361.

6. MacIntyre NR, Leatherman NE. Ventilatory muscle loads and the frequency-tidal volume pattern during inspiratory pressure-assisted (pressure-supported) ventilation. Am Rev Respir Dis 1990; 141: 327-331.

7. Nava S, Bruschi C, Rubini F, Palo A, Iotti G, Braschi A. Respiratory response and inspiratory effort during pressure support ventilation in COPD patients. Intensive Care Med 1995; 21: 871-879.

8. Field S, Grassino A, Sanci S. Respiratory muscle oxygen consumption estimated by the diaphragm pressuretime index. J Appl Physiol: Respirat Environ Exercise Physiol 1984; 57: 44-51.

9. Zanotti E, Rubini F, Iotti G, et al. Elevated static compliance of the total respiratory system: early predictor of weaning unsuccess in severe COPD patients mechanically ventilated. Intensive Care Med 1995; 21: 399-405.

10. Murray JF, Matthay MA, Luce JM, Flick MR. An expanded definition of the adult respiratory distress syndrome. Am Rev Respir Dis 1988; 138: 720-723.

11. MacIntyre NR. Respiratory function during pressure support ventilation. Chest 1986; 89: 677-683.

12. MacIntyre NR, Nishimura M, Usada Y, Tokioka H, Takezawa J, Shimada Y. The Nagoya conference on system design and patient-ventilator interactions during pressure support ventilation. Chest 1990; 97: 14631466.

13. Milic-Emili J, Mead JJ, Turner JD, Glauser FM. Improved technique for studying pleural pressure from esophageal balloons. J Appl Physiol 1964; 13: 207-211.

14. Baydur A, Behrakis PK, Zin WA, Jaeger MJ, MilicEmili J. A simple method for assessing the validity of 
the esophageal balloon technique. Am Rev Respir Dis 1982; 126: 788-791.

15. Appendini L, Patessio A, Zanaboni S, et al. Physiologic effects of positive end-expiratory pressure and mask pressure support during exacerbations of chronic obstructive pulmonary disease. Am J Respir Crit Care Med 1994; 149: 1069-1076.

16. Sassoon CSH, Light RW, Lodia R, Sieck GC, Mahutte CK. Pressure-time product during continuous positive airway pressure, pressure support ventilation, and TPiece during weaning from mechanical ventilation. $\mathrm{Am}$ Rev Respir Dis 1991; 143: 469-475.

17. Withelaw WA, Derenne JP, Milic-Emili J. Occlusion pressure as a measure of respiratory center output in conscious man. Respir Physiol 1975; 23: 181-199.

18. Rossi A, Gottfried SB, Zocchi L, et al. Measurement of static compliance of the total respiratory system in patients with acute respiratory failure during mechanical ventilation. Am Rev Respir Dis 1985; 131: 672-677.

19. Bates JHT, Rossi A, Milic-Emili J. Analysis of the behaviour of the respiratory system with constant inspiratory flow. J Appl Physiol 1985; 64: 441-450.
20. Rubini F, Rampulla C, Nava S. Acute effect of corticosteroids on respiratory mechanics in mechanically-ventilated patients with chronic airflow obstruction and acute respiratory failure. Am J Respir Crit Care Med 1994; 149: 306-310.

21. Rossi A, Gottfried SB, Higgs BD, Zocchi L, Grassino A, Milic-Emili J. Respiratory mechanics in mechanically-ventilated patients with acute respiratory failure. J Appl Physiol 1985; 58: 1849-1858.

22. Kochi T, Okubo S, Zin WA, Milic-Emili J. Flow and volume dependence of pulmonary mechanics in anesthetized cats. J Appl Physiol 1988; 64: 441-450.

23. Kimura T, Takezawa J, Nishiwaki K, Shimada Y. Determination of the optimal pressure support level evaluated by measuring transdiaphragmatic pressure. Chest 1991; 100: 112-117.

24. Mancebo J, Benito S, Martin M, Net A. Value of static compliance in predicting mortality in patients with acute respiratory failure. Intensive Care Med 1988; 14: 110-114.

25. Fernandez R, Benito S, Blanch L, Net A. Intrinsic PEEP: a cause of inspiratory muscle ineffectivity. Intensive Care Med 1988; 15: 51-52. 